\title{
Late Holocene environmental reconstructions and their implications on flood events, typhoon, and agricultural activities in NE Taiwan
}

\author{
L.-C. Wang ${ }^{1,2}$, H. Behling ${ }^{1}$, T.-Q. Lee ${ }^{3}$, H.-C. Li ${ }^{4}$, C.-A. Huh ${ }^{3}$, L.-J. Shiau ${ }^{5}$, and Y.-P. Chang ${ }^{6}$ \\ ${ }^{1}$ Department of Palynology and Climate Dynamics, Albrecht-von-Haller Institute for Plant Sciences, \\ University of Göttingen, 37073 Göttingen, Germany \\ ${ }^{2}$ Collection Management Department, National Taiwan Museum, Taipei 100, Taiwan \\ ${ }^{3}$ Institute of Earth Sciences, Academia Sinica, Taipei 128, Taiwan \\ ${ }^{4}$ Department of Geosciences, National Taiwan University, Taipei 106, Taiwan \\ ${ }^{5}$ Institute of Applied Geosciences, National Taiwan Ocean University, Keelung 202, Taiwan \\ ${ }^{6}$ Department of Oceanography, National Sun Yat-sen University, Kaohsiung 804, Taiwan
}

Correspondence to: L.-C. Wang (lwang6@uni-goettingen.de) and Y.-P. Chang (yuanpin.chang@mail.nsysu.edu.tw)

Received: 10 March 2014 - Published in Clim. Past Discuss.: 5 May 2014

Revised: 15 August 2014 - Accepted: 12 September 2014 - Published: 22 October 2014

\begin{abstract}
We reconstructed paleoenvironmental changes from a sediment archive of a lake in the floodplain of the Ilan Plain of NE Taiwan on multi-decadal resolution for the last ca. 1900 years. On the basis of pollen and diatom records, we evaluated past floods, typhoons, and agricultural activities in this area which are sensitive to the hydrological conditions in the western Pacific. Considering the high sedimentation rates with low microfossil preservations in our sedimentary record, multiple flood events were. identified during the period AD 100-1400. During the Little Ice Age phase 1 (LIA 1 - AD 1400-1620), the abundant occurrences of wetland plant (Cyperaceae) and diatom frustules imply less flood events under stable climate conditions in this period. Between AD 500 and 700 and the Little Ice Age phase 2 (LIA 2 - AD 1630-1850), the frequent typhoons were inferred by coarse sediments and planktonic diatoms, which represented more dynamical climate conditions than in the LIA 1. By comparing our results with the reconstructed changes in tropical hydrological conditions, we suggested that the local hydrology in NE Taiwan is strongly influenced by typhoontriggered heavy rainfalls, which could be influenced by the variation of global temperature, the expansion of the Pacific warm pool, and the intensification of El Niño-Southern Oscillation (ENSO) events.
\end{abstract}

\section{Introduction}

Western North Pacific tropical cyclones (TCs) can cause natural disasters associated with large-scaled catastrophic landslides which may have a huge impact on human life in the East Asian coastal areas (Tsou et al., 2011). High wind speeds and strong land precipitation caused by TCs produce flood and landslide disasters (Tsou et al., 2011). The factors that affect TC fluctuations were assumed from the recent 30-year typhoon-data-set simulation. The strength of TCs is strongly associated with the tropical-sea-surface temperature (SST) (Lin et al., 2008). Global warming will lead to an upward trend in TC destructive potential (Emanuel, 2005). The paths of TCs are influenced by the El Niño-Southern Oscillation (ENSO) through the shifts in the main genesis region in the West Pacific (Elsner and Liu, 2003). During El Niño events, TCs form further east with a northwestward recurving path. During La Niña years, TCs move straight with a westward path (Fig. 1). However, modern observed TC records are too short to understand climate factors and the environmental changes in a specific region. According to previous studies in East Asia, the amount of precipitation during the Holocene epoch was presumably influenced by the variation in the summer monsoon and its correlation with solar insolation (Liu et al., 2008; Qian et al., 2003; Varma et al., 2011; Wan et al., 2011; Zheng et al., 2013). Several studies suggest that the shifts in the northern limit of the intertropical 
convergence zone (ITCZ) influenced the tropical hydrology, then caused the drier Little Ice Age (LIA) on the East Asian continent (Hu et al., 2008; Zhang et al., 2008). This view has been challenged by findings of increased rainfall during the LIA in South China (Chen et al., 2005; Chu et al., 2002) and Taiwan (Chen et al., 2009; Wang et al., 2011, 2013). Such spatial variations in precipitation reflect the regional climate characteristics, such as monsoonal precipitation or TC-triggered heavy rainfall. However, studies on the influences of TC intensity and frequency on local hydrology during the Holocene epoch are rare (Chen et al., 2012; Wang et al., 2013; Woodruff et al., 2009), even though the hydrological conditions, especially flooding, on the East Asian coast are strongly affected by TCs today.

The Ilan Plain, located in northeastern Taiwan, is situated under the main paths of TCs from the western Pacific (Fig. 1). It is an ideal area for a paleo-typhoon study, but very little investigation has been done so far, despite its importance (Chen et al., 2012). In addition, the interaction between human activity and environment is a topic in paleoecology. Lin et al. (2007) suggested that the archeological hiatus in the Ilan Plain during the late Holocene correlated to frequent typhoons and landslides. However, direct evidence and precise agricultural-activity duration are lacking. Therefore, this study used the pollen and diatom records from highresolution lake sediments to detect the paleo-environment and anthropogenic impacts on NE Taiwan during the late Holocene. We assessed the role of frequent natural hazards on settlements during the past. We compared our data with other paleoclimatological records to understand the relationship between the precipitation in Ilan Plain and the typhoon activity in the West Pacific coastal area.

\section{Study area}

The study area, the Ilan Plain, is located on the northeastern coast of Taiwan and enclosed by steep mountains (Fig. 1). Only the eastern part is open and faces the North Pacific. Flooding is frequent in low elevated areas during heavy-rain days. The plain is an alluvial fan with an extremely high accumulation rate. The main source of the alluvium is the denudation from the mountain region among the Lanyang River system (Letouzey and Kimura, 1986). The superficial rocks of surrounding mountains consist of meta-sandstone, shale, and slate, while the alluviums of the plain are the mixture of stone, sand, silt, and clay.

The Ilan Plain belongs to the subtropical monsoon region. The climate is warm and humid. The Ilan weather station $\left(24^{\circ} 45^{\prime} 56^{\prime \prime} \mathrm{N}, 121^{\circ} 44^{\prime} 53^{\prime \prime} \mathrm{E}, 7.2 \mathrm{~m}\right.$ a.s.1.), reports a mean annual temperature of $22.5^{\circ} \mathrm{C}$ from data that have been collected since 1981 to 2010 . The mean annual precipitation is $2238 \mathrm{~mm}$. The extremely humid months are September, October, and November with precipitation rates more than $300 \mathrm{~mm}$ per month. The autumn rainfall maximum can be correlated to the late-season typhoon events and transient disturbances embedded in the northeasterly monsoon flow during the passage of cold fronts (Chen and Chen, 2003). The dry season is unclear because of the influences of the winter monsoon, which is characterized by northeasterly wind with cold and wet air blown from the North Pacific originating from the Mongolian Plateau (Fig. 1). According to the long-term Ilan meteorological record (1950-2010), the mean precipitation of typhoon season (June-November) represents a complicated pattern with ENSO intensity. It shows a basically negative correlation phase, but not significantly, on a statistic test $\left(R^{2}=0.10, p<0.05\right)$ (Fig. 2). However, the correlation coefficient increases for the recent 30 years $\left(1980-2010, R^{2}=0.23\right)$. The recent 50-year (1960-2009) pattern of average monthly rainfall distribution confirms that TC-induced rainfall is important on regulating seasonal rainfall (Kim et al., 2012). TC frequency and TC-triggered rainfall decrease in Ilan during El Niño years because mean steering flows become southerly and drive TCs to recurve northward toward Japan and the North Pacific (Chen et al., 2010).

The vegetation types of the lowland and hills of the Ilan Plain are assigned to the subtropical evergreen-rain-forest zone (Su, 1984), although the most plain area has been reclaimed for rice paddies. In the riverine or alluvial fan areas, Alnus formosana, Barringtonia racemosa, and Cephalanthus naucleoide are scattered. Poaceae and Cyperaceae dominate in the coastal marshland (Lin et al., 2007). According to the modern vegetation map of Taiwan (Fig. 1) (Chiou et al., 2009), the forest zone in the surrounding mountains, as well as the drainage basin of Lanyang River, is strongly influenced by altitude. Machilus thumnbergii, Castanopsis cuspidate, Lagerstroemia subcostata, and Adisia sieboldii are important and common woody trees in the lower montane evergreen broad-leave forests (LMF, < $1200 \mathrm{~m}$ a.s.l.). Cyclobalanopsis morri, Pinus taiwanensis, and Alnus formosana are the main species in montane mixed needle-broad-leave forests (MF, 1200-2200 $\mathrm{m}$ a.s.l.). The upper montane needle-leave forests (UMF - > $2200 \mathrm{~m}$ a.s.1.) are dominated by Tsuga chinensis var. formosana, and Abies kawakamii.

Dahu Lake (DHL) is located on the northwestern margin of the Ilan Plain (Fig. 1). DHL is a lowland lake (17 m a.s.1.) with an average water depth of $2 \mathrm{~m}$ and a surface area of about $106 \mathrm{~km}^{2}$. The lake is isolated and the primary water inputs are from rainfall, surface runoff from the catchment, and groundwater discharges. Lanyang River is the main river on the plain, located to the south of DHL. A previous study addressed the high sedimentation rates of DHL as a consequence of massive inputs of suspended material from overflows from the Lanyang River at various time intervals during the middle to late Holocene (Chen et al., 2012). 

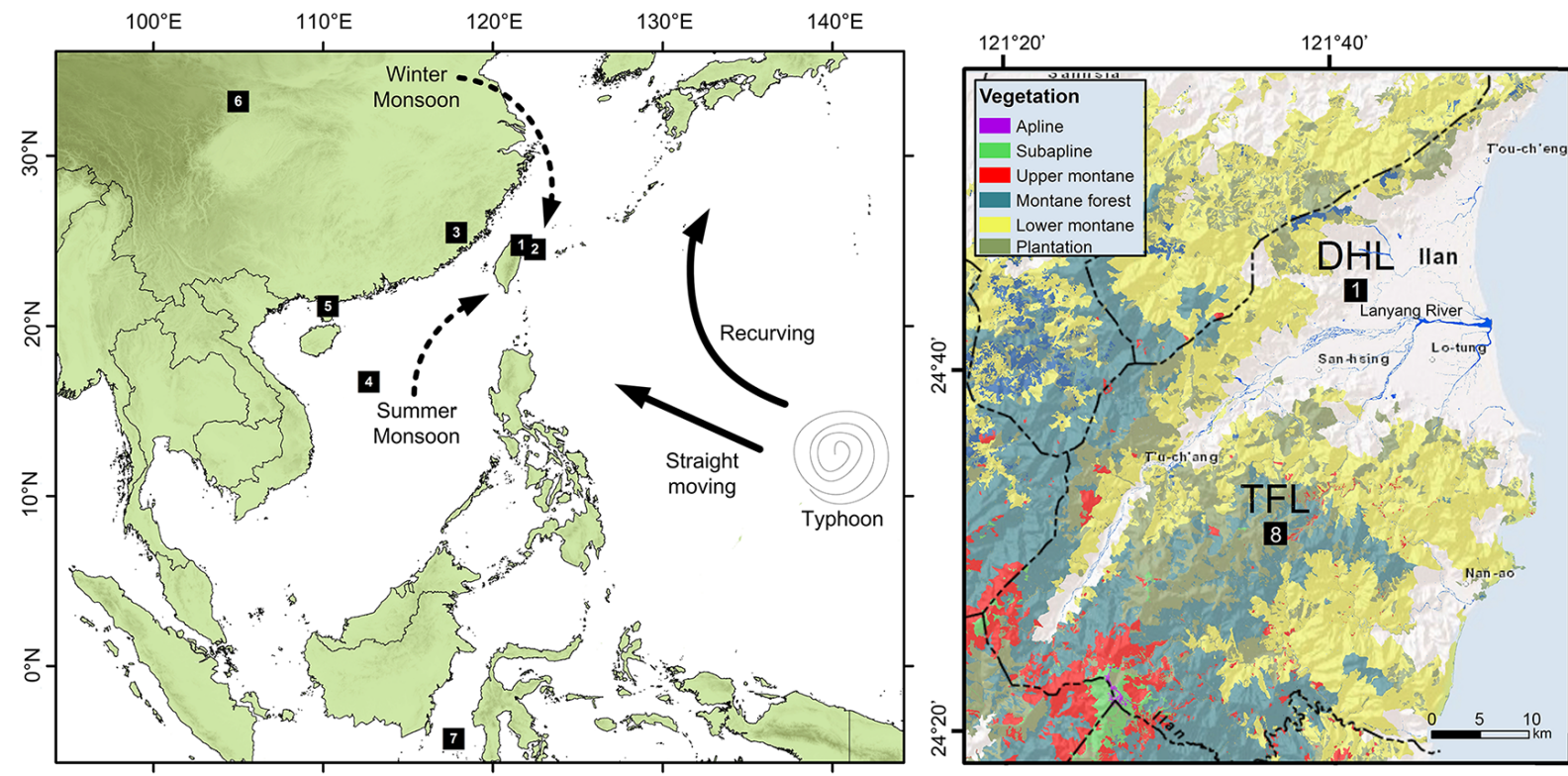

Figure 1. Maps showing the location of Dahu Lake (DHL) with modern vegetation cover (right). Locations (black squares) are used for discussions, as follows: (1) DHL; (2) South Okinawa Trough; (3) Fujian Province; (4) Cattle Pond, Dongdao Island; (5) Lake Huguang Maa; (6) Wanxiang Cave; (7) Makassar Strait; (8) Tsuifong Lake (TFL).
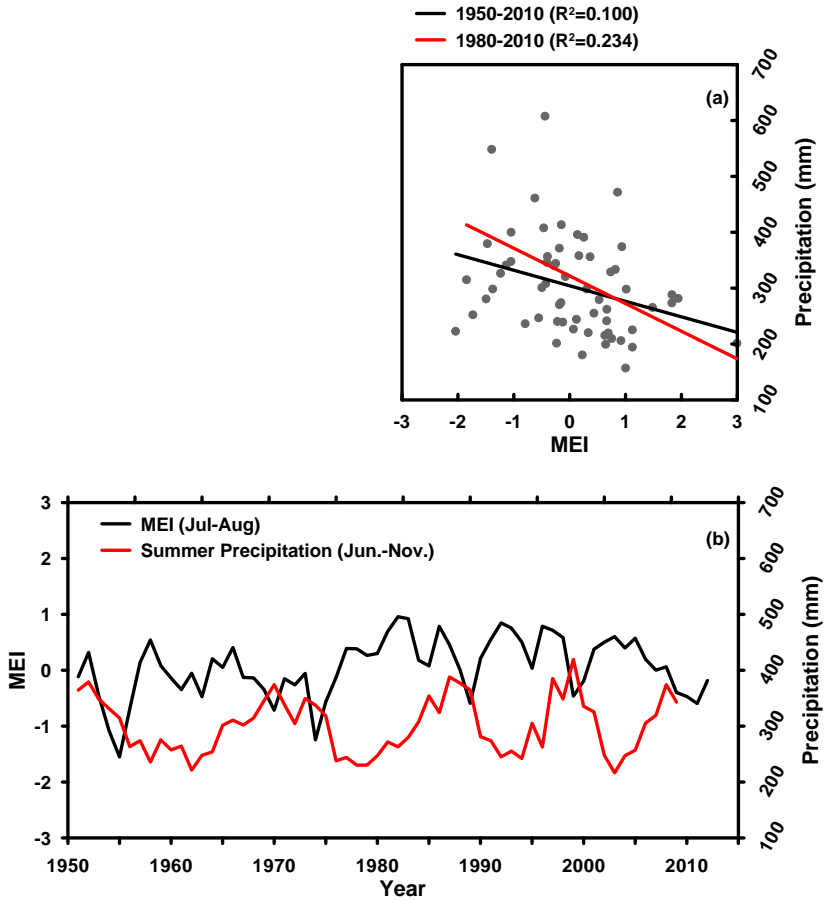

Figure 2. (a) Diagram shows statistic relationship between ENSO index (MEI) and monthly precipitation of typhoon season (JuneNovember). (b) The recent 60 year (1950-2010) mean precipitation data of typhoon season from the Ilan weather station overlaps with the MEI (Wolter and Timlin, 2011).

\section{Materials and methods}

\subsection{Coring and sampling}

A $35 \mathrm{~m}$ sediment core (DH-7B) was taken and reached to the bottom by using a stainless corer on a floating platform in the western area of DHL in January, 2008 (Chen et al., 2012). The sediment core was stored at $4{ }^{\circ} \mathrm{C}$ in a dark room. The core was subsampled at $1 \mathrm{~cm}$ intervals for pollen and diatom analysis.

The sediments of core DH-7B mainly consist of gray clay, and interrupted with 10 to $70 \mathrm{~cm}$ thick layers of sand, silt, and brown clay throughout the upper $1400 \mathrm{~cm}$ (Fig. 3). Sand layers are presented at a depth of 790-800 cm and $650-690 \mathrm{~cm}$, while the silt layers occur at a depth of $720-740 \mathrm{~cm}, 690$ $700 \mathrm{~cm}$, and $460-480 \mathrm{~cm}$. The brown clay layers are only found at a depth of $440-460 \mathrm{~cm}$ and in the upper $70 \mathrm{~cm}$.

\subsection{Stratigraphy and chronology}

The upper $1100 \mathrm{~cm}$ core sediments are composed of classic sediments. Sediments at $460-440 \mathrm{~cm}$ and in the uppermost $70 \mathrm{~cm}$ are organic, enriched brown clay, while the remaining core sediments consist of organic-poor clay, silt, and fine sand (Fig. 3).

Linear interpolation of four radiocarbon dates reported by Chen et al. (2012) and ${ }^{210} \mathrm{~Pb}$-derived sedimentation rate of the upper $23.5 \mathrm{~cm}$ were used to establish a revised age model of the core DH-7B (Fig. 3). The radiocarbon dating shows no reversal in ages, suggesting a continued and undisturbed deposition environment. For the chronology of ${ }^{210} \mathrm{~Pb}, 10$ 


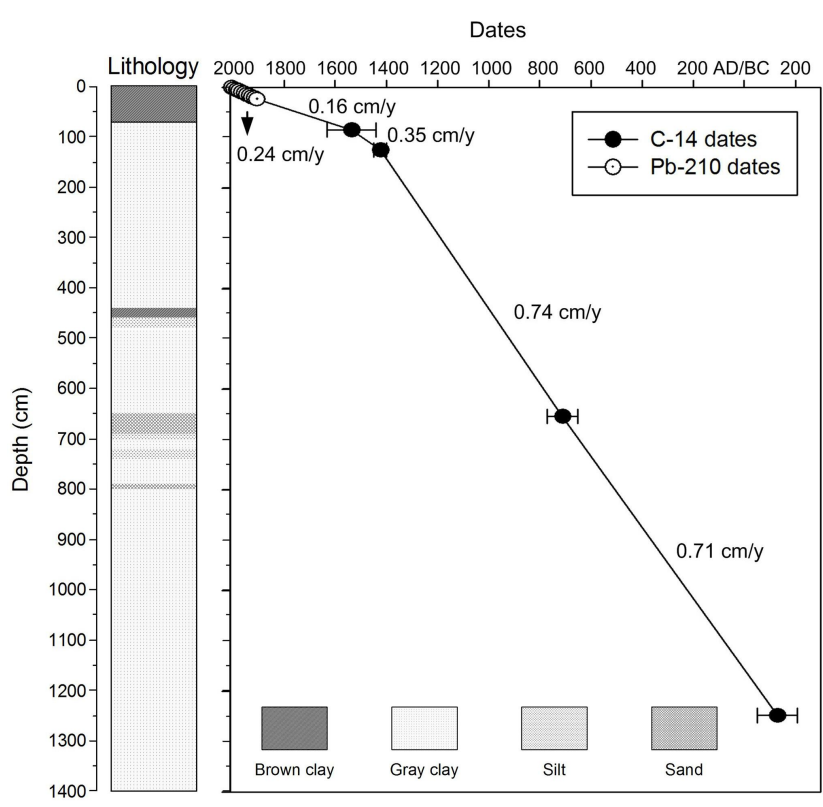

Figure 3. Lithology and age-depth profile of the studied sediment core from DHL with dates and estimated sedimentation rates.

samples taken from the upper $25 \mathrm{~cm}$ of the core were analyzed for ${ }^{210} \mathrm{Po}$ by $\alpha$-spectrometry, with ${ }^{209} \mathrm{Po}$ added as the yield determinant. More detailed procedures can be found in Huh and Su (2004). According to the age model, the upper $1100 \mathrm{~cm}$ of the core represented the records for the period of AD 100 to 2007.

Sedimentation rates are not consistent and have higher values below $130 \mathrm{~cm}$ (before $\mathrm{AD} 1400$ ) with values ranging from $0.74-0.71 \mathrm{~cm} \mathrm{y}^{-1}$. Above $130 \mathrm{~cm}$ (after AD 1400), sedimentation rates are low $\left(0.35-0.16 \mathrm{~cm} \mathrm{y}^{-1}\right)$. On the basis of the sedimentation rate and sample intervals, the time resolution of our proxies can attend to 20-25 years in resolution over the last 2 millennia.

\subsection{Pollen and diatom analysis}

For the extraction of pollen and diatoms, subsamples at 5$20 \mathrm{~cm}$ intervals $(0-300 \mathrm{~cm}$ core depth at $5 \mathrm{~cm}$ intervals; $300-$ $900 \mathrm{~cm}$ at $10 \mathrm{~cm}$ intervals; $900-1100 \mathrm{~cm}$ at $20 \mathrm{~cm}$ intervals) were used. The samples with low preservations of pollen or diatom, which counted less than 100 pollen grains or diatom valves, were not used for discussion. Below $1100 \mathrm{~cm}$ core depth, samples were not analyzed because of poor preservation of both microfossils.

The pollen extraction was treated following dense media methods (Nakagawa et al., 1998). In all, 5 grams of dry weight sediment were digested with $36 \% \mathrm{HCl}, 10 \% \mathrm{NaOH}$, repeatedly rinsed with distilled water 6-20 times. Samples were then concentrated using dense media (solution of density 1.88) and treated with acetolysis. One tablet with a given number of Lycopodium spores was added to each sample before chemical treatments for quantification. Pollen identifica- tion and counts were done with a $400 \times$ optical microscopy. With the help of the pollen and spores database of Taiwan (Huang, 1972, 1981), pollen grains were identified to the lowest taxonomic level. For most samples, 300 pollen grains were counted. Percentages are based on the total pollen sum. Fern spores and the green algae Pediastrum were not included, but presented as the percentages of the sum of all pollen.

On the basis of the modern vegetation map, the main tree pollen types were assigned into three groups: upper mountain forest (UMF), mountain forest (MF), and lower mountain forest (LMF). These three types of vegetation are typically found on mountains of the Taiwan island. The herbaceous pollen types were attributed to two groups by the habitats as either terrestrial (non-arboreal pollen - NAP) or aquatic types (wetland). The Poaceae pollen with a long axis of more than $40 \mu \mathrm{m}$ was identified as cultivated Poaceae (ItzsteinDavey et al., 2007), although other authors used $35 \mu \mathrm{m}$ as a separation criterion between cultivated and wild Poaceae (Wang et al., 2010b).

Diatom analysis followed the method described by Wang et al. (2013). Half gram of dry weight sediment was digested with $32 \% \mathrm{H}_{2} \mathrm{O}_{2}$ and $10 \% \mathrm{HCl}$, then mounted on slides using mounting media (Wako). A total of 300 diatom valves were identified and counted under $1000 \times$ optical microscopy. The identification of diatom species and their ecological interpretation is based on the freshwater diatom flora of Taiwan and collecting references therein (Charles, 1985; Krammer and Lange-Bertalot, 1986; Wang et al., 2010a; Wu et al., 2011). Thus, all diatom species were attributed to groups that correspond to preferred habitat types (planktonic, epiphytic, and benthic).

\subsection{Data analysis}

In order to mitigate the effect of rare taxa that poorly explain the complete trend of vegetation, only pollen taxa which occurred with a percentage value lager than $3 \%$ in at least three samples were used for numerical analyzes. The stratigraphic diagrams were created using Tilia and Tilia*Graph (Grimm, 1993) and the C2 program (version 1.5 for Windows) (Juggins, 2005). Pollen data were subjected by a cluster analysis using Edwards and Cavalli-Sforza's chord distance measure of CONISS in TGView to define the zonation.

The ordination analyzes and plotting were carried by using CANOCO (version 4.5) for Windows and CanoDraw (version 4.13) for Windows (Ter Braak and Smilauer, 2002). Pollen percentages were square-root transformed for the numerical analyses to remove the effect from dominant taxa and to optimize the signal-noise ratio (Jantz and Behling, 2012; Wang et al., 2014). Detrended correspondence analysis (DCA) yielded the length of the environmental gradients with the value 1.61 of standard deviation (SD). Thus, a linear ordination method (principle component analysis - PCA) is appropriate for these data sets. 


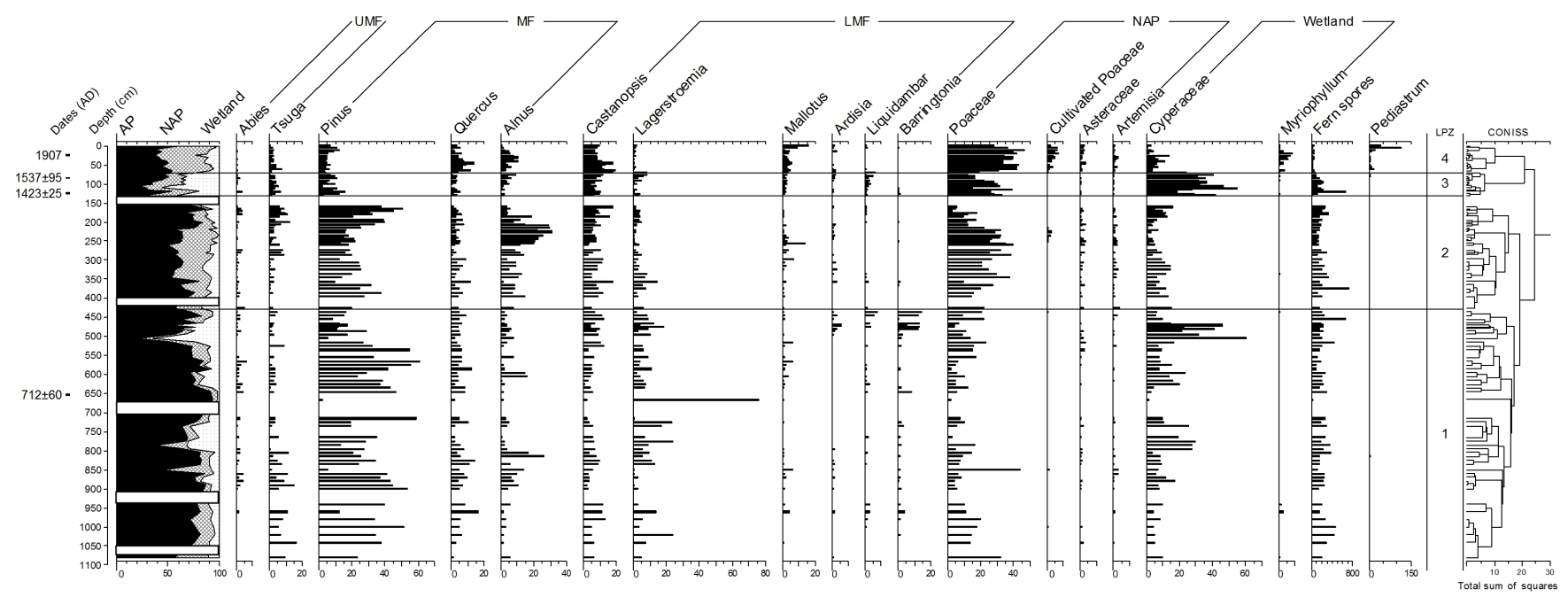

Figure 4. Pollen diagrams for selected taxa, denoted in percentage, are presented throughout the sediment core with respect to local pollen zones (LPZ). The percentages of pollen, fern spores, and green algae Pediastrum are based on the sum of total pollen. Intervals with low pollen preservation are denoted by shadow areas with white color.

\section{Results}

\subsection{Pollen and diatoms}

Due to the extremely poor preservation of microfossils in some samples, only 109 samples were used for pollen analysis and 35 samples for diatom analysis. Four local pollen zones (LPZs) were identified to be relying on pollen assemblages. All results are displayed with dendrograms (Fig. 4). The assemblages of pollen and diatoms have somehow coherent variations in core DH-7B (Fig. 5), which show both higher concentrations and component variations in organicrich layers (Fig. 6). The resemblance in trends enables the diatom assemblages to be assigned into four pollen zones, at the same depths, with pollen assemblages.

The LPZ 1 (core depth: $1100-440 \mathrm{~cm}$; age: AD 1001010) has a higher sedimentation rate $\left(0.71 \mathrm{~cm} \mathrm{y}^{-1}\right)$ with low pollen and diatom preservation. Arboreal pollen (AP) comprises $72 \%$ of the total pollen. UMF and MF pollen are the dominant pollen types, and Pinus is the most important taxa, averaging about $30 \%$ of the pollen sum. The pollen preservation is extremely low and the sediments consist of coarse silt and sand at depths between 700 and $650 \mathrm{~cm}$. However, LMF pollen Lagerstroemia has a maximum value of $76 \%$ at the depth of $665 \mathrm{~cm}$. In the upper part of the zone, sediments consist of silt and organic-rich brown clay at depths of $480-440 \mathrm{~cm}$. Wetland pollen, such as Cyperaceae, LMF pollen and riverine pollen Barringtoniai increased. Fern spores dominate with an average value of 225. Diatom valves, mostly benthic species, are merely found at the end of LPZ 1 (Fig. 5).

LPZ 2 (core depth: $440-130 \mathrm{~cm}$; age: AD 1010-1400) is characterized with poor diatom preservation and relatively high sedimentation rates $\left(0.74 \mathrm{~cm} \mathrm{y}^{-1}\right)$. Pollen concentration remains low. AP reaches $67 \%$ of the pollen sum with dominated by UMF and MF pollen. Pinus declines slightly to $24 \%$ on average. Alnus pollen becomes more important and averages at $12 \%$. The percentages of UMF pollen Abies and Tsuga are slightly higher than in Zone LPZ 1 . The percentage of Poaceae is much higher, especially in the middle part of the zone. Fern spores are slightly decreased, with a mean value of 205 .

In LPZ 3 (core depth: 130-70 cm; age: AD 1400-1620), the sedimentation rate declines from 0.35 to $0.16 \mathrm{~cm} \mathrm{y}^{-1}$. The pollen concentrations are much higher, but vary remarkably. With a marked decrease of UMF and MF pollen, AP decreases to $38 \%$, although the LMF pollen does not vary much. Barringtonia is almost completely absent. Cyperaceae is the most important taxa, with an average of $36 \%$. Fern spores are reduced $(\sim 183)$. Diatom concentration increases and epiphytic diatoms dominate the assemblages.

In LPZ 4 (core depth: 70-0 cm; age: AD 1620-2007), the sedimentation rate remains low and increases slightly during the last century. The pollen concentrations are high. AP is about $48 \%$ of the total pollen. Castanopsis is the dominant tree taxa compared with the percentage of other LMF taxa. Pollen values of Ardisia, Liquidambar, and Lagerstroemia are low. The zone is characterized by the increase in anthropogenic pollen, including wild and cultivated Poaceae, Asteraceae and Artemisia. Cyperaceae pollen remains low $(\sim 7 \%)$. Fern spores decrease markedly and the mean value is 39. Percentages of green algae Pedistrum peak at the end of the zone and reach the value of 116. Diatom concentrations are much higher than those in LPZ 3 and occur consistently throughout the zone. Planktonic diatoms and larger epiphytic diatoms (Cymbella tumida, Encyonema mesianum, 


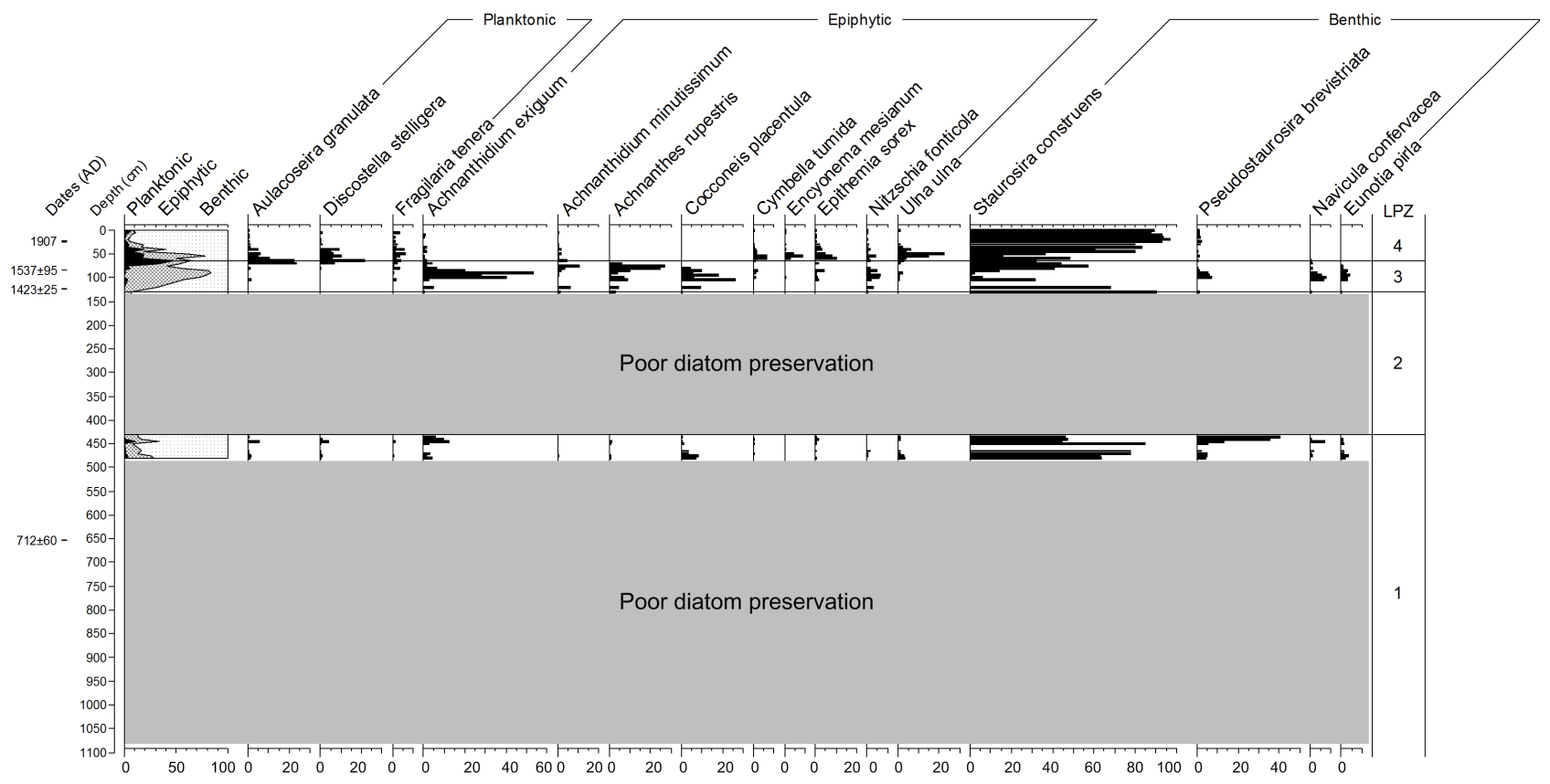

Figure 5. Sediment profiles of dominant planktonic, epiphytic, and benthic diatoms on the basis of pollen zones (LPZ).

Epithemia sorex, and Ulna ulna) show an increase trend during the lower part of the zone. Percentages of benthic diatoms, such as Staurosira construens, remain low at the beginning of the zone, but increase gradually towards the top.

\subsection{Principal Component Analysis}

The PCA pollen data show important data-set ordinations revealing the relationships between samples and pollen taxa (Fig. 6). The eigenvalues are 0.30 for the first component axis (PC1) and 0.20 for the second component axis (PC2). Along the PC1 axis, Poaceae and cultivated Poaceae represent the negative scores and correspond best to LPZ 4. Along the PC2 axis, all UMF and MF taxa have negative scores with good correlation to LPZ 1 and LPZ 2, while the Cyperaceae have the highest positive scores with a correlation to LPZ 3.

\section{Discussion}

\subsection{Proxies evaluation}

Diatoms are good indicators of water-quality conditions. High diatom concentrations can refer to stable lacustrine environments, while poor diatom preservation or abrupt concentration fluctuation can reflect frequent disturbances (Wang et al., 2014). Xu et al. (1996) suggested that pollen compositions had a marked difference between the alluvial and lacustrine sediments based on surface sediments studied in the North China Plain. The lacustrine sediments are characterized by high pollen concentration, while the alluvial sediments are characterized by more mountainous pollen and high variations in pollen taxa in different depositional faces. Chen et al. (2012) supposed that the illite and muscovite in the TFL sediment were delivered from the upstream of the adjacent Lanyang River (Fig. 6), where the outcrop consists of $30 \%$ illite and muscovite. Thus, the increase in illite and muscovite in the core sediments can be used as a proxy for Lanyang River overflow, which transports numerous inorganic clay minerals into DHL (Chen et al., 2012). Therefore, the low pollen grain concentration, as well as poor diatom valve preservation, but high illite and muscovite contents during LPZ 2 and LPZ 1, suggest numerous inputs of detrital matter from alluvium, indicating flood events.

Palynological data from lake sediments had been broadly used to indicate variations in paleovegetation within the pollen source area, from which most of the pollen grains originate (e.g., Sugita, 1993; Prentice, 1985). For the lacustrine sediments, the source of pollen is mainly from local vegetation which is delivered by wind. However, for the alluvium, fluvially transported pollen from river drainage system is a significant source of pollen, especially during flood periods (Brown, 1985; Chmura and Liu, 1990). According to the variations in pollen and diatom concentrations, the fluvial transport is dominated in LPZ 1 and LPZ 2 with UMF and MF pollen, especially Pinus. However, the distances between DHL and the nearby Pinus forest is more than $10 \mathrm{~km}$ (Fig. 1). In explaining this, we assumed that the markedly high occurrence of Pinus pollen (more than $30 \%$ ) in DHL was attributed to river overflows, with the pollen assemblage from river transport used for indicating the vegetation history in the river drainage area (Kröpelin et al., 2008). The 


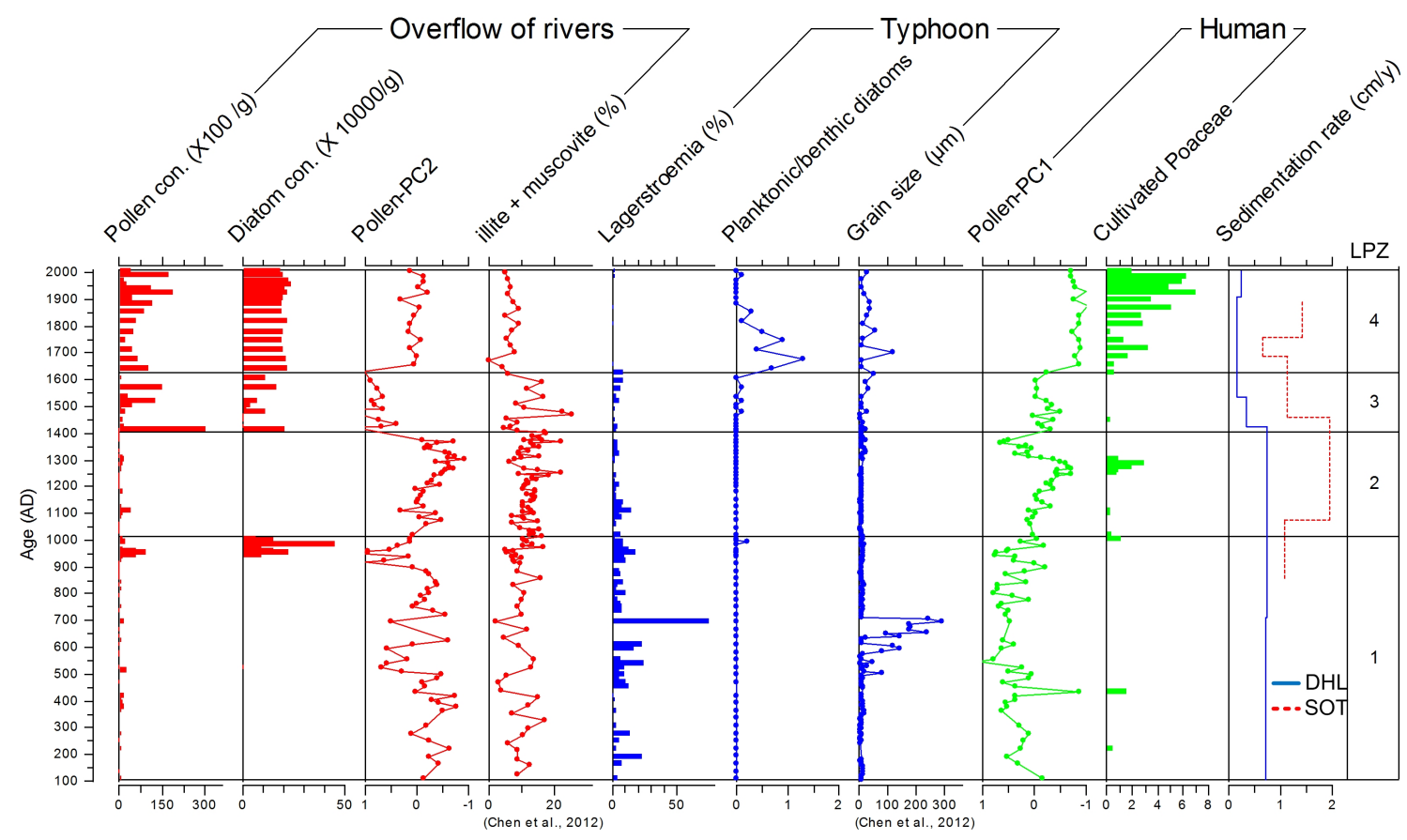

Figure 6. Principal components analysis biplot of pollen compositions in sediments from DHL. The first and second principal components (PC1 and PC2) explain $30 \%$ and $20 \%$, respectively, of the variation. The factor loadings of pollen abundance and the factor scores of sediment samples are plotted together in this diagram.

variations and percentages of Pinus in DHL are much higher than those in Yuanyang Lake (Chen and Wu, 1999), which has been located at the Lanyang River drainage area and the coast sites of the Ilan Plain (Lin et al., 2007) for the last 2000 years. Therefore, we assume that the higher percentages of UMF and MF pollen are due to resuspension of river deposits, corresponding to river-flood stages, rather than the regional vegetation transition. This assumption can be supported by PCA analysis. The axis of PC2 reveals the strong negative correlation with UMF and MF pollen, and fits well to LPZ 1 and LPZ 2, suggesting that the axis of PC2 is a good indicator of the flood intensity.

The percentage of Lagerstroemia reaches $78 \%$ in the middle part of LPZ 1. The abundance was much higher than that in the lowland Ilan Plain, where the percentage of Lagerstroemia varies below 10\% (Lin et al., 2007). The large deciduous tree, Lagerstroemia subcostata, is common in low altitude forests of the surrounding mountains in the Ilan Plain. These inputs could be attributed to the typhoontriggered local landslides and heavy rainfalls, which eroded the soil from Lagerstroemia forests, then transported it into DHL.

Distinct changes in the diatom assemblage within the lake can be related to changes in the aquatic conditions. The ratio of benthic and planktonic diatoms ( $\mathrm{P} / \mathrm{B}$ ratios) has been used to infer past fluctuations in lake level and precipitation (Laird et al., 2011). Based on this assumption, the variation in $\mathrm{P} / \mathrm{B}$ ratios in our study was used as a proxy of paleo-precipitation.
In Taiwan, the cultivated Poaceae (Oryza) have been used as a proxy for agricultural activities (Tsukada, 1967), while the wood of Lagerstroemia is an important burning material for ancient agricultural-activity processing by native people (Chen and Chen, 2009). The cultivated Poaceace is negatively correlated with the PC1 score (factor loading $=-0.7$ ), and shows an anti-phase with the occurrences of Lagerstroemia, a representative species of wild environment, inferring to the increased agricultural activities during the LPZ 1.

\subsection{Interpretation of paleoenvironment and their impact on agricultural activities}

Environmental changes were reconstructed according to the pollen and diatom records. The following discussion interprets the implications of the proxies presented for each zone and the extent to which DHL records reflect the fluvial plain evolution, local hydrology, and the traces of agricultural activities over the last 1900 years.

LPZ 1 (AD 100-1010) corresponds to the pre-Medieval Warm Period (pre-MWP) and is characterized by a high sedimentation rate and extremely low pollen concentration, along with poor diatom preservation. The high negative values of pollen PC2, along with high percentages of illite and muscovite, reflects numerous inputs from the overflow of the Langyang rivers, indicating that the DHL experienced frequent floods, reflecting the unstable hydrological conditions 
during the period. The floodplain landscape, along with the river system, is intensified by the synchronic increase in riverbank shrub and Barringtonia pollen in the sediment cores of DHL and coastal areas (Lin et al., 2007). Chen et al. (2012) applied the grain size in DHL sediments as an indicator of the input from the local watershed, indicating typhoons. Coincident increase in Lagerstroemia percentages $(>20 \%)$ and larger grain size during the period AD 500700 have been assumed as a signal of strong (or frequent) typhoon events. During the period AD 940-1010, the silt and organic-rich brown-clay sediments and high diatom concentration indicate the shortly lacustrine deposition, reflecting the mitigation of flood disturbances. The landscape of DHL temporally turns out to be a shallow lake surrounded with sedges, which is indicated by the dominance of benthic diatoms and Cyperaceae pollen.

The high positive values of pollen PC1 and low percentages of cultivated Poaceae imply little human impact in the study area. This assumption is strengthened by the hiatus of the archaeological records in Ilan during the period $450 \mathrm{BC}-$ AD 650 (Lin et al., 2004, 2007). Combining with the paleoenvironmental changes, the gap in the archaeological record can be corresponded to frequent nature hazards, such as floods and TCs during this period.

LPZ 2 (AD 1010-1400) corresponds to the Medieval Warm Period (MWP) and is characterized with higher sedimentation rate and poor diatom valve preservation, reflecting an alluvial plain environment. Low pollen concentration and high pollen PC2 indicates to the input from overflow of rivers and indicates that flooding occurred, agreeing by the increase in sedimentation rate in the South Okinawa Trough (SOT) (Wei et al., 2005) (Fig. 1), which implies more fluvial material inputs (Fig. 6). Pollen PC-2 varies little, inferring the high environmental stability. The stable hydrological condition during the period AD 1010-1200 in LPZ 2, and shallow lake criteria during the period AD 940-1010 in LPZ 1 are appropriately supported by the summary of 4000 -year palynological data in Taiwan, which indicated a relative stable climate during the period AD 760-1300 (Liew et al., 2014).

During this period forest disturbance by humans was confirmed by the rapid increase in pioneer forest, Alnus, Mallotus and a corresponding decline in ethnobotanical plants, Lagerstroemia. Agricultural activities were indicated by cultivated Poaceae and the increasing frequency of disturbance indicators, Poaceae, Asteraceae, and Artemisia. The anthropogenic proxy pollen $\mathrm{PC} 1$ indicates a clear agriculture period during the period AD 1250-1300 (Fig. 9). These results are confirmed by archaeological records, which indicate that agriculture in the study area was established in alluvial fans, riverine and littoral areas from around AD 1250 (Liu, 2000). During the period AD 1300-1400 intense flood events, inferred by pollen $\mathrm{PC} 2$, was presumably corresponded to the decline of agricultural activities.

Important characteristics of LPZ 3 (AD 1400-1620, corresponding to the LIA 1), are marked by the decline of

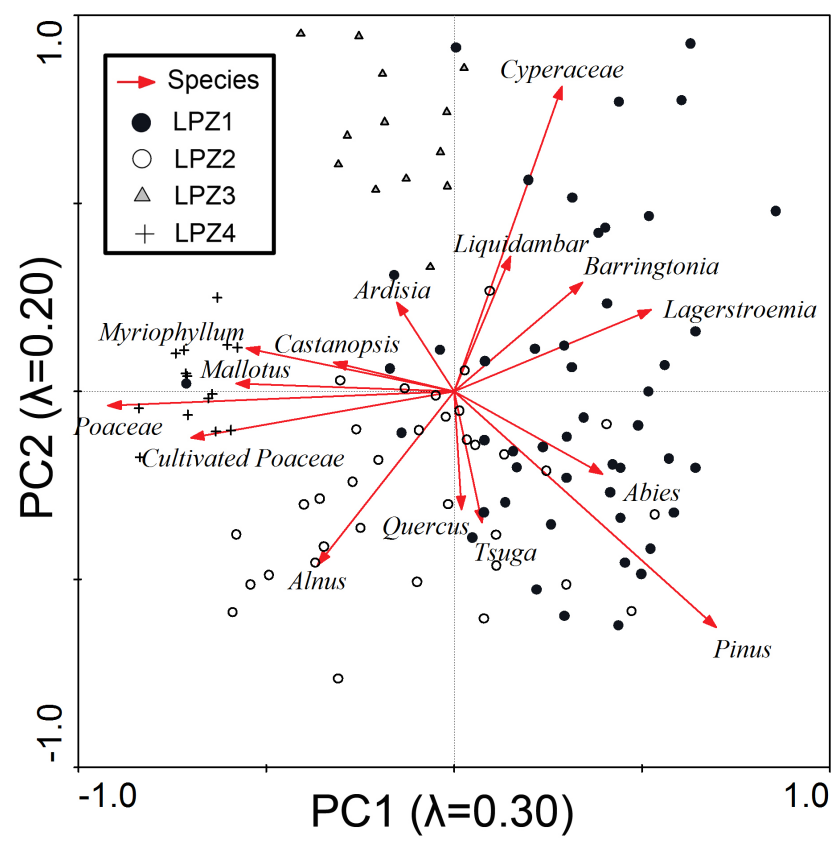

Figure 7. Pollens and diatoms based reconstruction of flood events, typhoon frequency, and human activities during the last 1900 years. Variations of pollen concentrations, diatom concentrations, Pollen PC2, the sum of illite and muscovite, percentages of Lagerstroemia pollen, ratio of planktonic/benthic diatom, grain size (Chen et al., 2012), Pollen PC1, percentage of cultivated Poaceae in DHL, and the sedimentation rate in DHL and SOT on the basis of pollen zones (LPZ).

sedimentation rates. Although the sediment still consists of organic-poor clay, the occurrence of diatom valves indicated that the DHL was situated in a transition phase between alluvial plain and lacustrine environment. The better preservation of pollen grains along with the high pollen PC2 values suggests that the DHL is little affected by river overflows. The marked decrease in high altitude pollen, mainly Pinus, and the disappearance of riverine taxa Barringtonia, indicates a reduction in flood events. The weaker capability of fluvial materials transportation is confirmed by the decrease in core SOT sedimentation rate (Fig. 7) (Li et al., 2011). The continuously high percentages of Cyperaceae pollen and epiphytic diatoms reflect that the wetland expanded in the vicinity of the DHL. Although the climate records in Taiwan indicated a wetter LIA (Liew et al., 2014; Wang et al., 2013, 2014), the reduction in flood events in the Ilan Plain during the early LIA was likely related to the local depositional environment in the alluvial plain transition phase. The human activities are reduced during this period. The weak agricultural activities are indicated by low cultivated Poaceae and pollen PC1 concentration.

Sediment changed from clay minerals to organic-rich sediments in the period of LPZ 4 (AD 1620-2007). The diatom concentration is high with little variation (Fig. 7), indicating 


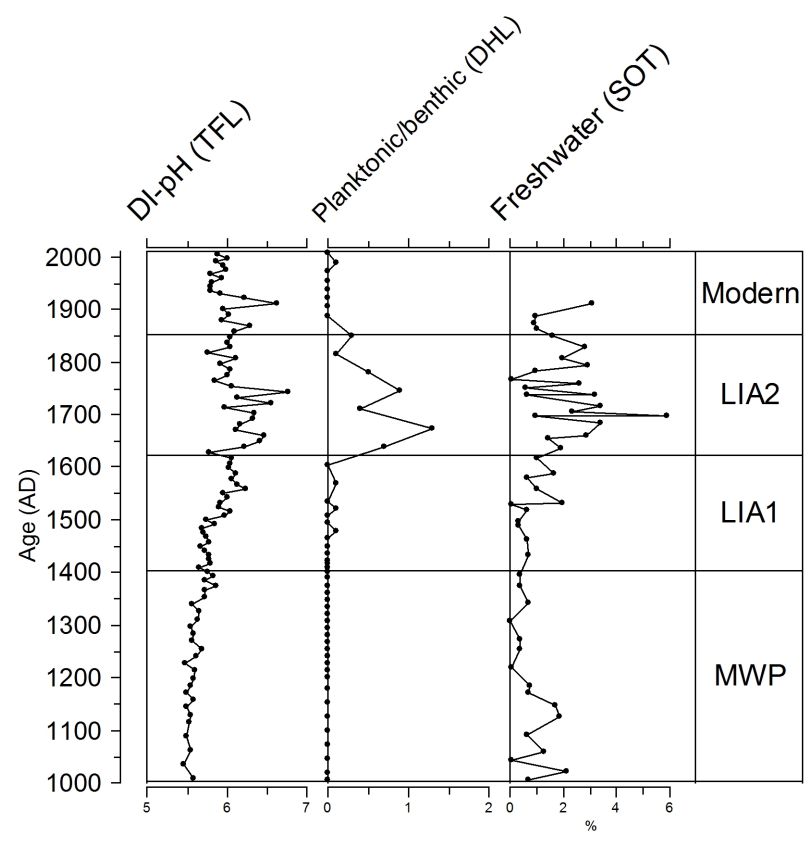

Figure 8. Variations of diatom-inferred precipitation during the last 1000 years in subalpine lake (TFL) (Wang et al., 2013), lowland lake (DHL), and offshore marine sediments (SOT) (Li et al., 2011).

the stable lacustrine environment.. During this period the DHL hydrological conditions are similar to today, which is an enclosed lake without the influence of alluviums. Although the flood variations cannot be reflected by the proxy of overflows, such as pollen PC2, the variations in diatom assemblages imply changes in the lake level. Coincident increase in the planktonic, benthic diatom (P/B) and grain size ratio during the period AD 1620-1850 (LIA 2), reflecting extreme rainfall (Fig. 6). The precipitation anomalies in NW Taiwan during LIA 2 are also inferred by the increase in diatom-derived $\mathrm{pH}$ proxy in the subalpine lake of NE Taiwan (Wang et al., 2013) and the increase in freshwater diatoms in SOT marine sediment (Fig. 8) (Li et al., 2011). Therefore, the occurrences of frequent TCs in NW Taiwan during LIA 2 were examined.

The increase in cultivated Poaceae with high negative pollen PC1 values suggests that agricultural activities occurred throughout the last 4 centuries. The higher lakenutrient level, due to human activities, is implied by the increase in Myriophyllum pollen (Grace and Wetzel, 1978) and the green algae Pediastrum (Weckström et al., 2010). According to the historical literature, Han Chinese moved into the northern Ilan Plain, then built irrigation systems for paddy-field farming in AD 1796. The clear increasing trend in cultivated Poaceae after AD 1800 may be linked to the irrigated agriculture of the Han Chinese, which increases the rice-cultivation area (Fig. 7).

\subsection{Hydrologic variability in the East Asian coast and its relationship with EASM, warm pool, and ENSO}

We compared the DHL flood intensity and typhoon frequency reconstructions with the main hydrological variation factors in the western North Pacific, including variations in ENSO (Moy et al., 2002), Indo-Pacific warm pool (IPWP) (Oppo et al., 2009), East Asia summer monsoon (EASM) (Zhang et al., 2009), East Asia winter monsoon (EAWM) (Yancheva et al., 2007), and the north-south migration of the ITCZ (Yan et al., 2011) over the last 2 millennia (Fig. 9). The data of frequent typhoon period (AD 500-700) and lacustrine period (AD 1620-2007) are excluded from the statistic test, because the flood proxy is insensitive during those periods. The flood intensity was correlated positively with the SST of IPWP $\left(R^{2}=0.24\right)$, but negatively with the proxy indices of the EASM $\left(R^{2}=0.14\right)$, the EAWM $\left(\mathrm{R}^{2}=0.21\right)$, and the ITCZ $\left(R^{2}=0.16\right)$. This result suggests that summer and winter rainfall of the Ilan Plain, influenced by the monsoonal strengths or the shift in ITCZ, is generally not high enough to trigger flood events in NE Taiwan. IPWP is the largest reservoir of warm surface water on the earth and the main source of heat and moisture in the atmosphere. When warmer SST occurs in the equatorial eastern Pacific Ocean, TCs tend to generate in the middle part of the equatorial $\mathrm{Pa}-$ cific, increasing the intensity of typhoons generated in the western Pacific warm pool (WPWP) (Barsugli and Sardeshmukh, 2002; Oppo et al., 2009). The frequent flood events during the pre-MWP and MWP in DHL could be the consequence of strong TC-triggered rainfalls. Our results also suggest that the variations in global temperature correlate to the strength of TCs that are intense in the MWP and weak in the LIA 1 (Emanuel, 2005).

The records of pollen, diatoms, and grain size in the DHL sediments show the frequent typhoon activity during the period $\mathrm{AD}$ 500-700 and the LIA 2 in NE Taiwan with the negative correlation with ENSO intensity (Fig. 9). However, stronger typhoon activities in Japan were recorded during the period AD 900-1100, showing a positive correlation with ENSO intensity (Woodruff et al., 2009). This inconsistent pattern found in Japan and Taiwan fits the modern observation of shifting TC tracks during El Niño periods. During El Niño years, the shifted center of WPWP from the western Pacific to the central Pacific enhances the occurrences of TCs in this region. They then move northward directly by attacking Japan without passing through Taiwan (Elsner and Liu, 2003). Therefore, Chen et al. (2012) suggested that the inconsistent paleo-typhoon record between Taiwan and Japan is relative to the shift in the TC tracks influenced by the modification of hydrological conditions of WPWP during ENSO intervals (Fogarty et al., 2006; Huang and Xu, 2010). In La Niña years, increased SSTs in the western Pacific, caused by moving westerly from the WPWP center, then raise the generate opportunities of TCs in this region. The occurrences of TC in western Pacific then favor moving directly northward 


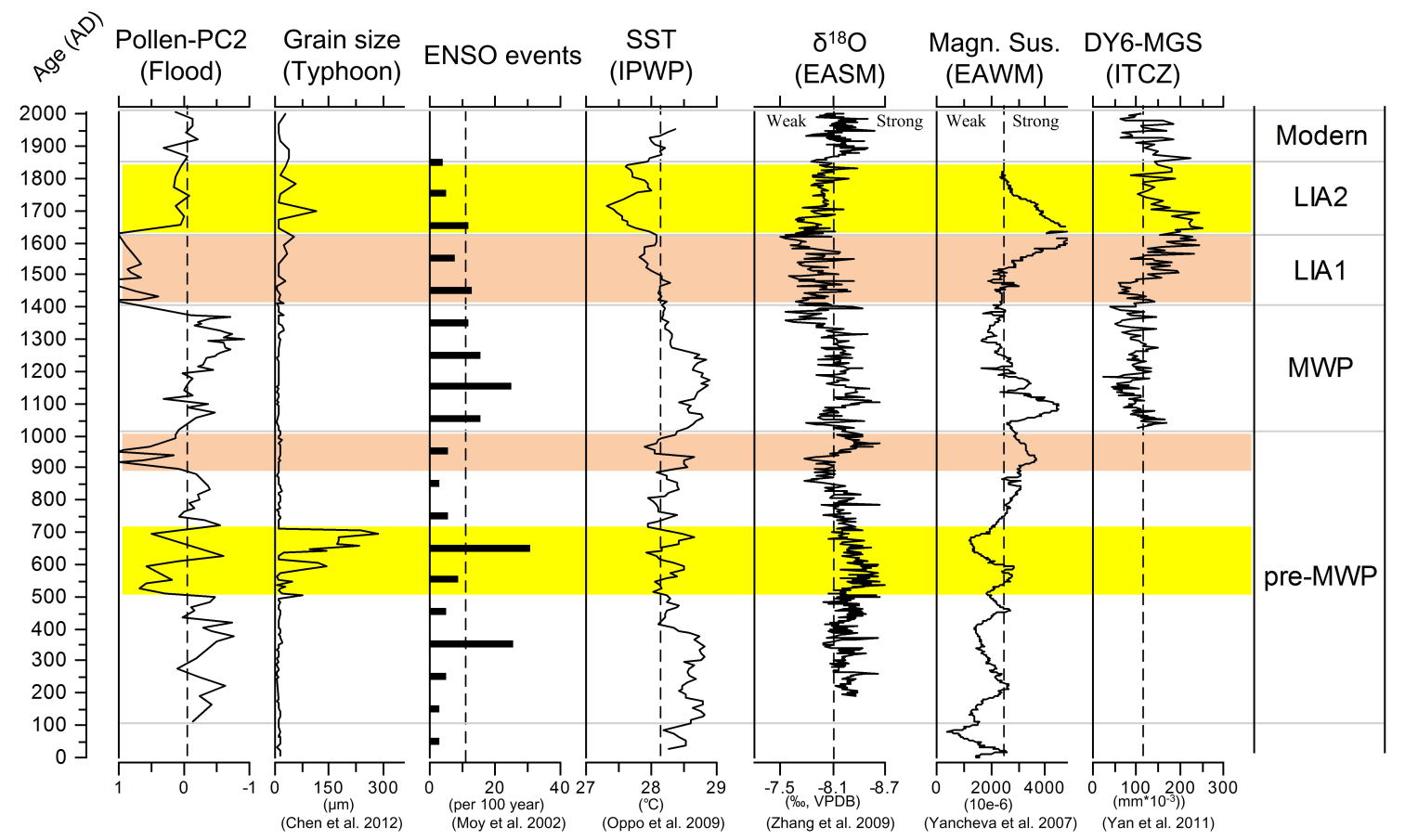

Figure 9. Variation of flood events and typhoon frequency in Taiwan over the last 1900 years by comparing with reconstructed proxy records of ENSO events (Moy et al., 2002), IPWP (SST of Makassar Strait) (Oppo et al., 2009), East Asia summer monsoon (EASM - $\delta^{18} \mathrm{O}$ speleothem from Wanxiang Cave) (Zhang et al., 2009), East Asian winter monsoon (EAWM - magnetic susceptibility from lake sediments of Lake Huguang Maar) (Yancheva et al., 2009), and the shifts of ITCZ (grain size from lake sediments from Cattle Pond, Dongdao Island) (Yan et al., 2011). Yellow shades indicate periods with frequently occurring typhoons, while the red shades indicate a transition phase of alluvial plain with little flood disturbance.

to hit Taiwan. This phenomena agrees with the statistical study of 50 years of typhoon records in Fujian (Fig. 1), revealing that the number of TCs affecting Fujian is, in general, higher during La Niña years (Yin et al., 2010). Thus, the precipitation anomaly caused by frequent typhoons during the period AD 500-700 and the LIA 2 may correlate to TC track shifts during La Niña-like periods, which caused the asymmetrical distribution in local precipitation superimposed on the regional hydrological pattern.

\section{Conclusions}

DHL sediment-core analysis derived from the floodplain in NE Taiwan provides a multi-decadal record of hydrological variations and clear evidence of agricultural activities over the last 2000 years. The globally warm period during the period AD 100-1400 (Pre-MWP, MWP) is characterized by high sedimentation rates and low microfossil preservations, inferring the strong influences caused by river overflows. $P i$ nus pollen unearthed from the flooding sediments was the most abundant composition during this stage. This finding reflects that multiple flood events were common during this period. A short shallow-lake period, due to the reduction of floods, has been found during the AD 940-1010 period, as well as the frequent typhoon events that occurred during the period AD 500-700. The globally cool period, LIA 1, is found in our record, inferring the transient phase of alluvial plain development discovered at AD 1400. At the same time, wetland pollen, Cyperaceae, and epiphytic diatoms dominated the records. The climatic conditions changed to more humid conditions, possibly indicating frequent typhoons during AD 1630-1850, where the plankton diatom reached its culmination. The increased impact of human agricultural activities is recorded during the ages of AD 1250-1300 and in the last $\sim 400$ years. It seems to be associated strongly with stable environmental conditions. Based on the comparisons with reconstructed warm-pool proxy, ENSO, monsoon, and ITCZ, the local hydrology of the coastal region of Taiwan is strongly affected by the rainfalls triggered by typhoons, influenced by the variation in global temperature, warm-pool expansion, and the intensification of ENSO events, rather than the precipitation influenced by the monsoonal intensity or the shift in the ITCZ. 
Acknowledgements. We thank Masanobu Yamamoto (Hokkaido University) and two anonymous reviewers for their constructive comments. We appreciate the financial support provided by a grant from the National Science Council (NSC 100-2611-M-110-011-, NSC 101-2116-M-002-007-, NSC 101-2611-M-110-003-, NSC 102-2917-I-564-058, MOST 103-2811-M-194-010), and the Open Fund of Key Laboratory of Chinese Academy of Geological Sciences (KERDC201301). This research was also funded by Asia-Pacific Ocean Research Center located in National Sun Yat-sen University, Taiwan and Interchange Association, Japan. Kaoru Kashima (Kyushu University) is acknowledged for allowing a diatom analysis to be conducted in that laboratory.

This Open Access Publication is funded by the University of Göttingen.

Edited by: M. Yamamoto

\section{References}

Barsugli, J. J. and Sardeshmukh, P. D.: Global Atmospheric Sensitivity to Tropical SST Anomalies throughout the IndoPacific Basin, J. Climate, 15, 3427-3442, doi:10.1175/15200442(2002)015<3427:GASTTS>2.0.CO;2, 2002.

Brown, A. G.: The potential use of pollen in the identification of suspended sediment sources, Earth Surf. Proc. Land., 10, 27-32, doi:10.1002/esp.3290100106, 1985.

Charles, D. F.: Relationships between surface sediment diatom assemblages and lakewater characteristics in Adirondack Lakes, Ecology, 66, 994-1011, 1985.

Chen, W. T. and Chen, H. W.: The Plants and Homeland of Bei-nan People, Natl. Mus. Prehistory Press Taitung Taiwan Chin., 2009.

Chen, C. S. and Chen, Y. L.: The rainfall characteristics of Taiwan, Mon. Weather Rev., 131, 1323-1341, 2003.

Chen, H.-F., Wen, S.-Y., Song, S.-R., Yang, T.-N., Lee, T.-Q., Lin, S.-F., Hsu, S.-C., Wei, K.-Y., Chang, P.-Y., and Yu, P.-S.: Strengthening of paleo-typhoon and autumn rainfall in Taiwan corresponding to the Southern Oscillation at late Holocene, J. Quaternary Sci., 27, 964-972, doi:10.1002/jqs.2590, 2012.

Chen, J., Wan, G., Zhang, D. D., Chen, Z., Xu, J., Xiao, T., and Huang, R.: The "Little Ice Age" recorded by sediment chemistry in Lake Erhai, southwest China, Holocene, 15, 925-931, doi:10.1191/0959683605hl863rr, 2005.

Chen, J.-M., Li, T., and Shih, C.-F.: Tropical Cyclone- and Monsoon-Induced Rainfall Variability in Taiwan, J. Climate, 23, 4107-4120, doi:10.1175/2010JCLI3355.1, 2010.

Chen, S. H. and Wu, J. T.: Paleolimnological environment indicated by the diatom and pollen assemblages in an alpine lake in Taiwan, J. Paleolimnol., 22, 149-158, 1999.

Chen, S.-H., Wu, J.-T., Yang, T.-N., Chuang, P.-P., Huang, S.-Y., and Wang, Y.-S.: Late Holocene paleoenvironmental changes in subtropical Taiwan inferred from pollen and diatoms in lake sediments, J. Paleolimnol., 41, 315-327, 2009.

Chiou, C.-R., Chen, T.-Y., Liu, H.-Y., Wang, J.-C., Yeh, C. L., and Hsieh, C.-F.: Modern vegetation map of Taiwan, Forestry Bureau, Council of Agriculture Executive Yuan, R. O. C. Taiwan, Taipei, 2009.
Chmura, G. L. and Liu, K.-B.: Pollen in the lower Mississippi River, Rev. Palaeobot. Palynol., 64, 253-261, doi:10.1016/00346667(90)90140-E, 1990.

Chu, G., Liu, J., Sun, Q., Lu, H., Gu, Z., Wang, W., and Liu, T.: The "Mediaeval Warm Period" drought recorded in Lake Huguangyan, tropical South China, Holocene, 12, 511516, doi:10.1191/0959683602hl566ft, 2002.

Elsner, J. B. and Liu, K. B.: Examining the ENSO-typhoon hypothesis, Clim. Res., 25, 43-54, 2003.

Emanuel, K.: Increasing destructiveness of tropical cyclones over the past 30 years, Nature, 436, 686-688, doi:10.1038/nature03906, 2005.

Fogarty, E. A., Elsner, J. B., Jagger, T. H., Liu, K., and Louie, K.: Variations in typhoon landfalls over China, Adv. Atmos. Sci., 23, 665-677, doi:10.1007/s00376-006-0665-2, 2006.

Grace, J. and Wetzel, R.: The production biology of Eurasian watermilfoil (Myriophyllum spicatum L.): a review, J. Aquat. Plant Manage., 16, 1-11, 1978.

Grimm, E.: TILIA: A Pollen Program for Analysis and Display, Ill. State Mus, Springf., IL, 1993.

Hu, C., Henderson, G. M., Huang, J., Xie, S., Sun, Y., and Johnson, K. R.: Quantification of Holocene Asian monsoon rainfall from spatially separated cave records, Earth Planet. Sc. Lett., 266, 221-232, doi:10.1016/j.epsl.2007.10.015, 2008.

Huang, F. and Xu, S.: Super typhoon activity over the western North Pacific and its relationship with ENSO, J. Ocean Univ. China, 9, 123-128, doi:10.1007/s11802-010-0123-8, 2010.

Itzstein-Davey, F., Atahan, P., Dodson, J., Taylor, D., and Zheng, H.: A sediment-based record of Lateglacial and Holocene environmental changes from Guangfulin, Yangtze delta, eastern China, Holocene, 17, 1221-1231, doi:10.1177/0959683607085128, 2007.

Jantz, N. and Behling, H.: A Holocene environmental record reflecting vegetation, climate, and fire variability at the Páramo of Quimsacocha, southwestern Ecuadorian Andes, Veg. Hist. Archaeobot., 21, 169-185, doi:10.1007/s00334-011-0327-x, 2012.

Juggins, S.: C2 Version 1.5: software for ecological and palaeoecological data analysis and visualisation, University of Newcastle, Newcastle, 2005.

Kim, J.-H., Wu, C.-C., Sui, C.-H. and Ho, C.-H.: Tropical cyclone contribution to interdecadal change in summer rainfall over South China in the early 1990 s, Terr. Atmos. Ocean. Sci., 23, 4958, doi:10.3319/TAO.2011.08.26.01, 2012.

Krammer, K. and Lange-Bertalot, H.: Süswasserflora von Mitteleuropa: Bacillariophyceae, Stuttg. Gustav Fish., Germany, 1-4, 1986.

Kröpelin, S., Verschuren, D., Lézine, A.-M., Eggermont, H., Cocquyt, C., Francus, P., Cazet, J.-P., Fagot, M., Rumes, B., Russell, J. M., Darius, F., Conley, D. J., Schuster, M., von Suchodoletz, H., and Engstrom, D. R.: Climate-driven ecosystem succession in the Sahara: the past 6000 years, Science, 320, 765 768, doi:10.1126/science.1154913, 2008.

Laird, K. R., Kingsbury, M. V., Lewis, C. F. M., and Cumming, B. F.: Diatom-inferred depth models in 8 Canadian boreal lakes: inferred changes in the benthic: planktonic depth boundary and implications for assessment of past droughts, Quaternary Sci. Rev., 30, 1201-1217, doi:10.1016/j.quascirev.2011.02.009, 2011. 
Letouzey, J. and Kimura, M.: The Okinawa trough: genesis of a back-arc basin developing along a continental margin, Tectonophysics, 125, 209-230, 1986.

Li, D., Jiang, H., Li, T., and Zhao, M.: Late Holocene paleoenvironmental changes in the southern Okinawa trough inferred from a diatom record, Chin. Sci. Bull., 56, 1131-1138, doi:10.1007/s11434-011-4369-3, 2011.

Liew, P.-M., Wu, M.-H., Lee, C.-Y., Chang, C.-L. and Lee, T.-Q.: Recent 4000 years of climatic trends based on pollen records from lakes and a bog in Taiwan, Quat. Int., doi:10.1016/j.quaint.2014.05.018, in press, 2014.

Lin, S. F., Liew, P. M., and Lai, T. H.: Late Holocene pollen sequence of the Ilan Plain, northeastern Taiwan and its environment and climatic implications, Terr. Atmos. Ocean. Sci., 15, 111-132, 2004.

Lin, S. F., Huang, T. C., Liew, P. M., and Chen, S. H.: A palynological study of environmental changes and their implication for prehistoric settlement in the Ilan Plain, northeastern Taiwan, Veg. Hist. Archaeobot., 16, 127-138, 2007.

Lin, I.I., Wu, C.-C., Pun, I.-F. and Ko, D.-S.: Upper-Ocean Thermal Structure and the Western North Pacific Category 5 Typhoons. Part I: Ocean Features and the Category 5 Typhoons' Intensification, Mon. Wea. Rev., 136, 3288-3306, 2008.

Liu, J., Wang, B., and Yang, J.: Forced and internal modes of variability of the East Asian summer monsoon, Clim. Past, 4, 225233, doi:10.5194/cp-4-225-2008, 2008.

Liu, Y. C.: The importance of Ilan archaeology in Taiwan, Lan J. Hist., 43, 3-27, 2000.

Moy, C. M., Seltzer, G. O., Rodbell, D. T., and Anderson, D. M.: Variability of El Niño/Southern Oscillation activity at millennial timescales during the Holocene epoch, Nature, 420, 162-165, doi:10.1038/nature01194, 2002.

Nakagawa, T., Brugiapaglia, E., Digerfeldt, G., Reille, M., De Beaulieu, J., and Yasuda, Y.: Dense-media separation as a more efficient pollen extraction method for use with organic sediment/deposit samples: comparison with the conventional method, Boreas, 27, 15-24, 1998.

Oppo, D. W., Rosenthal, Y., and Linsley, B. K.: 2000-year-long temperature and hydrology reconstructions from the Indo-Pacific warm pool, Nature, 460, 1113-1116, doi:10.1038/nature08233, 2009.

Qian, W., Hu, Q., Zhu, Y., and Lee, D.-K.: Centennial-scale dry-wet variations in East Asia, Clim. Dynam., 21, 77-89, doi:10.1007/s00382-003-0319-3, 2003.

$\mathrm{Su}, \mathrm{H}$. J.: Studies on the climate and vegetation types of the natural forests in Taiwan (II): altitudinal vegetation zones in relation to temperature gradient, Q. J. Chin. For., 17, 57-73, 1984.

Ter Braak, C. J. and Smilauer, P.: Canoco 4.5: Reference Manual and Canodraw for Windows, User's Guide: software Form Canonical Community Ordination (version 4.5), Microcomputer Power, Ithaca, New York, 2002.

Tsou, C.-Y., Feng, Z.-Y., and Chigira, M.: Catastrophic landslide induced by Typhoon Morakot, Shiaolin, Taiwan, Geomorphol., 127, 166-178, 2011.

Tsukada, M.: Vegetation in subtropical Formosa during the Pleistocene glaciations and the Holocene, Palaeogeogr. Palaeocl., 3, 49-64, 1967.
Varma, V., Prange, M., Lamy, F., Merkel, U., and Schulz, M.: Solarforced shifts of the Southern Hemisphere Westerlies during the Holocene, Clim. Past, 7, 339-347, doi:10.5194/cp-7-339-2011, 2011.

Wan, N.-J., Li, H.-C., Liu, Z.-Q., Yang, H.-Y., Yuan, D.-X., and Chen, Y.-H.: Spatial variations of monsoonal rain in eastern China: instrumental, historic and speleothem records, J. Asian Earth Sci., 40, 1139-1150, doi:10.1016/j.jseaes.2010.10.003, 2011.

Wang, L.-C., Behling, H., Lee, T.-Q., Li, H.-C., Huh, C.-A., Shiau, L.-J., Chen, S.-H., and Wu, J.-T.: Increased precipitation during the Little Ice Age in northern Taiwan inferred from diatoms and geochemistry in a sediment core from a subalpine lake, J. Paleolimnol., 49, 619-631, doi:10.1007/s10933-0139679-9, 2013.

Wang, L.-C., Lee, T.-Q., Chen, S.-H., and Wu, J.-T.: Diatoms in Liyu Lake, Eastern Taiwan, Taiwania, 55, 228-242, 2010a.

Wang, X., Li, Y., Xu, Q., Cao, X., Zhang, L., and Tian, F.: Pollen assemblages from different agricultural units and their spatial distribution in Anyang area, Chin. Sci. Bull., 55, 544-554, doi:10.1007/s11434-009-0480-0, 2010b.

Wang, L. C., Wu, J. T., Lee, T. Q., Lee, P. F., and Chen, S. H.: Climate changes inferred from integrated multi-site pollen data in northern Taiwan, J. Asian Earth Sci., 40, 1164-1170, doi:10.1016/j.jseaes.2010.06.003, 2011.

Wang, Y., Herzschuh, U., Shumilovskikh, L. S., Mischke, S., Birks, H. J. B., Wischnewski, J., Böhner, J., Schlütz, F., Lehmkuhl, F., Diekmann, B., Wünnemann, B., and Zhang, C.: Quantitative reconstruction of precipitation changes on the NE Tibetan Plateau since the Last Glacial Maximum - extending the concept of pollen source area to pollen-based climate reconstructions from large lakes, Clim. Past, 10, 21-39, doi:10.5194/cp-10-21-2014, 2014.

Weckström, K., Weckström, J., Yliniemi, L.-M., and Korhola, A.: The ecology of Pediastrum (Chlorophyceae) in subarctic lakes and their potential as paleobioindicators, J. Paleolimnol., 43, 6173, doi:10.1007/s10933-009-9314-y, 2010.

Wei, K.-Y., Mii, H., and Huang, C.-Y.: Age model and oxygen isotope stratigraphy of site ODP1202 in southern Okinawa Trough, northwestern Pacific, Terr. Atmos. Ocean. Sci., 16, 1-17, 2005.

Wolter, K. and Timlin, M. S.: El Niño/Southern Oscillation behaviour since 1871 as diagnosed in an extended multivariate ENSO index (MEI. ext), Int. J. Climatol., 31, 1074-1087, doi:10.1002/joc.2336, 2011.

Woodruff, J. D., Donnelly, J. P., and Okusu, A.: Exploring typhoon variability over the mid-to-late Holocene: evidence of extreme coastal flooding from Kamikoshiki, Japan, Quaternary Sci. Rev., 28, 1774-1785, doi:10.1016/j.quascirev.2009.02.005, 2009.

Wu, J.-T., Babu, B., Chou, C.-L., and Saraswathi, S. J.: Freshwater Diatom Flora of Taiwan, Biodiversity Research Center, Academia Sinica, Taipei, Taiwan, 2011.

Yan, H., Sun, L., Oppo, D. W., Wang, Y., Liu, Z., Xie, Z., Liu, X., and Cheng, W.: South China Sea hydrological changes and Pacific Walker Circulation variations over the last millennium, Nat. Commun., 2, 293, doi:10.1038/ncomms1297, 2011. 
Yancheva, G., Nowaczyk, N. R., Mingram, J., Dulski, P., Schettler, G., Negendank, J. F. W., Liu, J., Sigman, D. M., Peterson, L. C., and Haug, G. H.: Influence of the intertropical convergence zone on the East Asian monsoon, Nature, 445, 74-77, 2007.

Yin, Y., Gemmer, M., Luo, Y., and Wang, Y.: Tropical cyclones and heavy rainfall in Fujian Province, China, Quat. Int., 226, 122128, doi:10.1016/j.quaint.2010.03.015, 2010.
Zhang, P., Cheng, H., Edwards, R. L., Chen, F., Wang, Y., Yang, X., Liu, J., Tan, M., Wang, X., Liu, J., An, C., Dai, Z., Zhou, J., Zhang, D., Jia, J., Jin, L., and Johnson, K. R.: A test of climate, sun, and culture relationships from an 1810-year Chinese cave record, Science, 322, 940-942, doi:10.1126/science.1163965, 2008.

Zheng, W., Wu, B., He, J., and Yu, Y.: The East Asian Summer Monsoon at mid-Holocene: results from PMIP3 simulations, Clim. Past, 9, 453-466, doi:10.5194/cp-9-453-2013, 2013. 